Acta Sci. Pol. Technol. Aliment. 20(2) 2021, 149-163

pISSN 1644-0730

eISSN 1898-9594

http://dx.doi.org/10.17306/J.AFS.2021.0857

ORIGINAL PAPER

Received: 9.07.2020

Accepted: 8.12.2020

\title{
AÇAÍ (EUTERPE OLERACEA MART.) REDUCES THE INFLAMMATORY RESPONSE TRIGGERED IN VITRO BY THE ANTIPSYCHOTIC DRUG OLANZAPINE IN RAW 264.7 MACROPHAGE CELLS
}

\author{
Marcelo S. Fernandes ${ }^{1}$, Alencar K. Machado 2 , Charles E. Assmann ${ }^{3}$, \\ Eduardo N. Andrade4, Verônica F. Azzolin ${ }^{5}$, Marta M. M. F. Duarte ${ }^{6}$, \\ Pedro A. S. do Prado-Lima ${ }^{7}$, Rogerio T. Riffel ${ }^{8}$, Ednea A. Maia-Ribeiro9, \\ Francine C. Cadoná ${ }^{10}$, Raquel Praia ${ }^{11}$, Fernanda Barbisan ${ }^{12 凶}$, Ivana B. M. da Cruz ${ }^{5}$
}

${ }^{1}$ Medicine Department, Universidade Federal da Fronteira Sul

R. Capitão Araújo 20, 99010-121 Passo Fundo, Brazil

${ }^{2}$ Biomedicine Department, Universidade Franciscana

Rua dos Andradas 1614, 97010-032 Santa Maria, Brazil

${ }^{3}$ Graduate Program in Biological Sciences: Toxicological Biochemistry, Universidade Federal de Santa Maria

Av. Roraima 1000, 97105-900 Santa Maria, Brazil

${ }^{4}$ Biogenomics Laboratory, Department of Morphology, Universidade Federal de Santa Maria

Av. Roraima 1000, 97105-900 Santa Maria, Brazil

${ }^{5}$ Graduate Program in Gerontology, Universidade Federal de Santa Maria

Av. Roraima 1000, 97105-900 Santa Maria, Brazil

${ }^{6}$ Aesthetics Department, Universidade Luterana do Brasil

BR 287, Km 252, 97170-000 Santa Maria, Brazil

${ }^{7}$ Brain Institute, Pontífica Universidade Católica

Av. Ipiranga 6690, 90610-000 Porto Algre, Brazil

${ }^{8}$ Medicine, Universidade Fronteira Sul

R. Capitão Araújo 20, 99010-121 Passo Fundo, Brazil

${ }^{9}$ Research, Fundação Universidade Aberta da Terceira Idade

${ }^{10}$ Biomedicine Departamente, Universidade Franciscana

R. dos Andradas 1614, 97010-030 Santa Maria, Brazil

${ }^{11}$ Research Fundação Universidade Aberta do Amazonas

Av. Santo Antonio 70, 69029-040 Manaus, Brazil

${ }^{12}$ Gerontology, Universidade Federal de Santa Maria

Av. Roraima 1000, building 19, room 3102, 97105-900 Santa Maria, Brazil

\begin{abstract}
Background. Açaí (Euterpe oleracea Mart), a Brazilian fruit, is considered a "superfruit" due its energetic properties and bioactive compounds. The açai's anti-inflammatory effects could attenuate the undesirable metabolic and pro-inflammatory side effects triggered by some antipsychotic drugs, such as Olanzapine (OLZ). It is possible to infer that açai supplement could potentially minimize the adverse effects of OLZ.

Aim. This study tested the potential in vitro effects of açai hydroalcoholic extract on the inflammatory activation of the RAW 264.7 macrophage line triggered by OLZ antipsychotic drugs.

Materials and methods. An in vitro protocol was performed using commercial RAW 264.7 macrophages, cultured under sterile conditions at $37^{\circ} \mathrm{C}$ with $5 \% \mathrm{CO}_{2}$ saturation. Initially, a pharmacological curve was defined to determine the concentration of Olanzapine to be used. After this, the cells were supplemented with different concentrations of hydroalcoholic extract of açaí, which had been previously chemically characterized.
\end{abstract}


After 24 and 72 hours of treatment, oxidative and inflammatory tests were performed. Therefore, the aim of this study was to verify whether the hydroalcoholic extract of açaí can modulate the oxy-inflammatory response of olanzapine in vitro.

Results. From a preliminary analysis, the açai extract at $5 \mathrm{mg} / \mathrm{mL}$ presented higher activity against inflammation triggered by OLZ $(0.03 \mu \mathrm{g} / \mathrm{mL})$. At this concentration, açai was able to reduce several oxidative and inflammatory markers triggered by OLZ $(0.03 \mu \mathrm{g} / \mathrm{mL})$ exposure, such as nitric oxide (NO), reactive oxygen species (ROS), and pro-inflammatory cytokine levels (IL-1b, IL-6, TNF-a, IFN-g) caused by OLZ $(0.03 \mu \mathrm{g} / \mathrm{mL})$. Moreover, açaí reverted the levels of anti-inflammatory cytokine IL-10 that had been dropped by OLZ exposure to their pre-exposure treatments.

Conclusions. The results suggest that açai extract could be useful in attenuating the peripheral inflammatory states triggered by OLZ. Additional pre-clinical and clinical investigations could be useful in testing therapeutic açai extract supplements.

Keywords: inflammation, cytokines, amazon fruit, food supplement

\section{INTRODUCTION}

The Amazonian tropical rainforest region has a large diversity of fruits that are habitually consumed by native populations. Some fruits have become popular around the world, such as açai (Euterpe olerace$a e$, Mart.), which is considered to be a "superfruit" due its energetic properties (Alessandra-Perini et al., 2018). Complementary investigations have also described that açai contains important bioactive molecules including $\alpha$-tocopherol, anthocyanins (cyanidin 3-glycoside and cyanidin 3-rutinoside), and other flavonoids (Alqurashi et al., 2016; Gouvêa et al., 2012). The açai's chemical matrix could explain several biological properties of this fruit, including antioxidant, genoprotective, anti-inflammatory and antimicrobial effects (Borges et al., 2019; Dias-Souza et al., 2018; Favacho et al., 2011; Yamaguchi et al., 2015). Machado et al. (2016), also suggested that açai could protect and reverse mitochondrial dysfunctions in neural cells. Previous in vivo experiments have described that açai presents antiaterosclerotic effects by improving HDL-cholesterol metabolism and regulation of hepatic lipogenesis and cholesterol excretion (De Oliveira et al., 2015; Feio et al., 2012; Sadowska-Krępa et al., 2015). Moreover, a recent review performed by de Almeida Magalhães et al. (2020) compiled evidence that açai could present several properties related to the treatment and prevention of some chronic diseases such as anxiety, diabetes, hypertension, and hyperlipidemia.

From these results, it is plausible to infer that açai supplements could be helpful in the control of some chronic non-transmissible diseases, and this hypothesis has previously been tested in several studies (Choi et al., 2017; de Moura and Resende, 2016; Pala et al., 2018). Therefore, it is possible that açai supplementation could also attenuate some negative side effects triggered by pharmacological drugs such as antipsychotics. This is the case for olanzapine (OLZ), an atypical antipsychotic drug of the thienobenzodiazepine class, that blocks multiple neurotransmitter receptors, including the $\mathrm{D}_{2}$ and $5-\mathrm{HT}_{2 \mathrm{~A}}$ receptors. This drug has been used for the treatment of schizophrenia, including in children and adolescents (Komossa et al., 2010; Krause et al., 2018), in the therapeutic maintenance of bipolar disorder (Lindström et al., 2017), to manage agitation in adults with progressive dementia (Farlow et al., 2017) and in the treatment of Huntington's Disease (Dale and Duijn et al., 2015). Moreover, OLZ has been used to attenuate chemotherapy-induced nausea and vomiting, including in children less than 13 years old (Yoodee et al., 2017). However, OLZ has side effects which trigger metabolic alterations including increase in body mass index (IMC), visceral fat, myotonia and diabetes mellitus type 2 (Galling et al., 2016; Gilles et al., 2010; Larsen et al., 2017). These side effects seem to be associated with chronic oxi-inflammatory states in peripheral and adipocyte tissue triggered by OLZ administration (Sárvári et al., 2014).

In this context, we hypothetized that an açai supplement obtained using a hydroalcoholic extraction, 
which has low levels of fat and glucose molecules, could offer potential therapeutic action against the inflammatory state triggered by OLZ-exposure. To test this hypothesis, an in vitro study was conducted using the commercial RAW 264.7 macrophage cell line exposed to OLZ and açai extract.

\section{MATERIALS AND METHODS}

\section{Chemicals and equipment}

All chemicals and reagents used in this study were of analytical grade and purchased from either Merck (Darmstadt, Germany) or Sigma-Aldrich Co. (St. Louis, MO, USA). Plastics and reagents used for the cell culture procedures were acquired from Gibco ${ }^{\mathrm{TM}}$ (Thermo Fisher Scientific; Grand Island, NY, USA). Molecular biology reagents were purchased from TRIzol reagent (Thermo Fisher Scientific; Grand Island, NY, USA), iScript cDNA synthesis kit (Bio-Rad Laboratories; Hercules, CA, USA), DNase (Invitrogen Life Technologies; Carlsbad, CA, USA), QuantiFast SYBR Green PCR Kit (Qiagen, Hilden, Germany). Picogreen analysis was performed using Invitrogen ${ }^{\mathrm{TM}}$ Quant-iT ${ }^{\mathrm{TM}}$ PicoGreen ${ }^{\mathrm{TM}}$ dsDNA Assay Kit, while Spectrophotometric and fluorimetric analysis were performed in a SpectraMax ${ }^{\circledR}$ i3x Multi-Mode Microplate Reader; Molecular Devices, (Sunnyvale, CA, USA) equipment.

\section{General experimental design}

An in vitro protocol was performed using a commercial RAW 264.7 macrophage cell line (ATCC ${ }^{\circledR}$ TIB-71 $^{\mathrm{TM}}$ ) obtained from the American Type Culture Collection (ATCC ${ }^{\circledR}$, Manassas, VA, USA), cultured under standardized conditions. The cells were cultured using $\mathrm{Dul}$ becco's Modified Eagle Medium (DMEM) with 10\% fetal bovine serum (FBS), supplemented with $1 \%$ penicillin/streptomycin and 1\% anfotericine $\mathrm{B}$ antifungal. The cell cultures were maintained at $37^{\circ} \mathrm{C}$ in a humidified atmosphere of $5 \% \mathrm{CO}_{2}$ and expanded to obtain the optimal amount for the experiments.

The general protocols used here were similar to those previously described by Barbisan et al. (2017), Duarte et al. (2018), Fernandes et al. (2019), involving in vitro psychotropic drug analysis on macrophage inflammatory response. As macrophages are highly sensitive to antigens and other antigenic factors, in the presence of these molecules, intense cellular proliferation and morphological changes occurs. These alterations, especially cellular proliferation in $72 \mathrm{~h}$ cell cultures, can be used as markers of the inflammatory activation of immune cells. The pro-inflammatory effects of OLZ at different concentrations were determined by Fernandes et al. (2019). OLZ at a concentration $0.03 \mu \mathrm{g} / \mathrm{mL}$ was used in the experiments, since this represents the OLZ values expected to have a clinical effect and to be in the plasmatic therapeutic range of this drug.

The therapeutic values of OLZ plasma are set out in the guidelines for therapeutic drug monitoring in neuropsychopharmacology (Mauri et al., 2018). Phytohemagglutinin (PHA) antigen $(125 \mu \mathrm{g} / \mathrm{mL})$ was used as a positive inflammatory control group (Duarte et al., 2018).

Macrophages were concomitantly exposed to the proinflammatory OLZ concentration with açaí extract at different concentrations $(0.01,0.05,0.1,1,5$, and 10 $\mu \mathrm{g} / \mathrm{mL}$ ). The chosen açai concentration was based on a previous study performed by Machado et al. (2016). The potential anti-inflammatory effects of açaí on the inflammatory response triggered by OLZ was also evaluated using cellular proliferation and complementary tests involving modulation of oxidative, inflammatory and apoptotic biomarkers at protein and gene levels. All protocols were triplicated from independent experiments.

\section{Açaí extract preparation and chemical characterization}

The present investigation is part of a project previously approved by the Brazilian Environmental Ministry to access the components of the genetic patrimony in national territory (no. 010547/2013-4) according to the Brazilian Legislation (no. 2186-16). The açai hydroalcoholic extract with low concentrations of fatty acids used in the experiments had previously been prepared and chemically characterized. Therefore, the main results of the açai extract characterization used here were previously described by Machado et al. (2016). In brief, açaí fruits were obtained from Manaus city (Amazonas state) and a hydroalcoholic extract was prepared from skin and pulp fractions (21-day extraction in $70 \%$ absolute ethanol: $30 \%$ distilled water, $\mathrm{v}: \mathrm{v}$; at a concentration of $300 \mathrm{mg} / \mathrm{mL}$ ). After this, the 
açai extract was lypholyzed and the main bioactive molecules were quantified by high performance liquid chromatography (HPLC-DAD) using a Shimadzu Prominence Auto Sampler (SIL-20A) system (Shimadzu, Kyoto, Japan). The main compounds identified and quantified in the açaí hydroalcoholic extract were $(\mathrm{mg} / \mathrm{g})$ orientin $(8.05 \pm 0.03), p$-coumaric acid (3.52 \pm 0.01 ), apigenin (3.29 \pm 0.01$)$, cyanidin-3-0-glucoside (2.62 \pm 0.01$)$, luteolin $(2.57 \pm 0.02)$, epicatechin (2.37 $\pm 0.02)$, vitexin $(2.19 \pm 0.01)$ and chrysin $(1.83 \pm 0.01)$. Moreover, gallic, chlorogenic, and caffeic acids, and catechin were also detected and quantified $(<1 \mathrm{mg} / \mathrm{g}$; Machado et al., 2016).

A previous study using a neuroblastoma cell line (SHSY-5Y) showed that concentrations of açai extract ranging from $0.005 \mu \mathrm{g} / \mathrm{mL}$ to $100 \mu \mathrm{g} / \mathrm{mL}$ did not present cytotoxic effects, thus increasing cell culture viability (Machado et al., 2016). These results were used as reference in the choice of açai concentrations tested here.

\section{Cell proliferation analysis}

Macrophage cellular proliferation in $72 \mathrm{~h}$ cell cultures indicates a pro-inflammatory response (Duarte et al., 2018; Fernandes et al., 2019). Therefore, a preliminary analysis of the pro-inflammatory effects of OLZ and its reversion by açai supplementation in macrophage cells was determined by cell proliferation analysis using the de MTT (3-(4,5-dimethylthiazol-2-yl)-2,5-diphenyltetrazolium bromide) tetrazolium method. This is a reduction assay evaluated using macrophage cultures using a protocol modified from Mosmann et al. (1983). Briefly, the cells were seeded in 96-well plates at a final concentration of $2 \times 10^{5} \mathrm{cells} / \mathrm{mL}$, and an MTT reagent was added to the cells at a final concentration of $0.5 \mathrm{mg} / \mathrm{mL}$. After $1 \mathrm{~h}$ of incubation at $37^{\circ} \mathrm{C}$, formazan crystals were solubilized using dimethylsulfoxide (DMSO) and the absorbance was recorded at $560 \mathrm{~nm}$ wavelength using a plate reading spectrophotometer (SpectraMax ${ }^{\circledR}$ i3x Multi-Mode Microplate Reader; Molecular Devices, Sunnyvale, CA, USA).

We performed the Picogreen $\AA$, ultrasensitive to quantify double-stranded DNA as a complementary test of cell proliferation. The protocol used here is an adaptation of Yang et al. (2006) where, briefly, cells at $2 \times 10^{5}$ cells $/ \mathrm{mL}$ were lysed with $0.1 \%$ triton, centrifuged at $200 \mathrm{gs}$ for $15 \mathrm{~min}$, before the supernatant was discarded. The total DNA content was determined with the addition of $10 \mu \mathrm{l}$ of picogreen reagent, and the sample fluorescence was measured on a black 96-well microplate at the following wavelengths: excitation $480 \mathrm{~nm}$, emission $520 \mathrm{~nm}$.

\section{Cell cycle analysis}

Cell cycle analysis also indicates a pro-inflammatory response and in this study was performed using a flow cytometry approach similar to that described by Azzolin et al. (2016). In short, the cells were seeded in 6-well plates and, after $72 \mathrm{~h}$ of treatment, underwent resuspension in $70 \%$ ethanol and were kept overnight at $-20^{\circ} \mathrm{C}$. Next, the cells were resuspended in $500 \mu \mathrm{L}$ of the staining solution prepared in PBS: $50 \mu \mathrm{g} / \mathrm{mL}$ PI, $100 \mu \mathrm{g} / \mathrm{mL}$ RNase and $0.05 \%$ Triton X-100, and incubated at $37^{\circ} \mathrm{C}$ for $40 \mathrm{~min}$. After that, cell cycle analysis was carried out using BD Accuri ${ }^{\text {TM }} \mathrm{C} 6$ equipment.

\section{Assessment of ROS and NO levels}

The levels of reactive oxygen species (ROS) and NO were quantified in macrophages exposed to OLZ and açai. Oxidative stress was assessed after $72 \mathrm{~h}$ by measuring the total level of reactive oxygen species (ROS) in RAW 264.7 cells using the 2,7-dichlorodihydrofluorescein diacetate (DCFH-DA) assay. DCFH-DA is a nonfluorescent chemical that is deacetylated by mitochondrial esterase enzymes to DCFH, which reacts with ROS and becomes DCF, a fluorescent molecule. The fluorescence was recorded at an excitation wavelength of $488 \mathrm{~nm}$ and an emission wavelength of $525 \mathrm{~nm}$ (Halliwell and Whiteman et al., 2004). A measurement of the NO levels was determined after $72 \mathrm{~h}$ following the Griess modified method (Tatsch et al., 2011). In short, RAW 264.7 cells were incubated at room temperature with the Griess reagent for $10 \mathrm{~min}$ and the absorbance was recorded at $550 \mathrm{~nm}$ wavelength.

\section{Cytokine and caspase imunoassays}

The modulation of pro-inflammatory and anti-inflammatory cytokines by macrophages exposed to OLZ and açai at $5 \mu \mathrm{g} / \mathrm{mL}$ concentration was also evaluated considering a previous study performed by Machado et al. (2016) suggesting that its concentration presented higher protective effects against mitochondrial dysfunction triggered by rotenone exposure. Quantification of cytokines was performed using a similar method 
described by Barbisan et al. (2017). Furthermore, caspases (CASP) apoptotic caspase markers were also evaluated among these treatments. Both cytokine and apoptotic markers were quantified using immunological assays as previously described (Da Cruz Jung et al., 2016). Briefly, a supernatant culture medium was used as a sample to quantify the levels of CASP-8 (sensitivity: $0.124 \mathrm{ng} / \mathrm{mL}$, range detection: $0.312-20 \mathrm{ng} / \mathrm{mL}$ ), CASP-3 (sensitivity: $0.056 \mathrm{ng} / \mathrm{mL}$, range detection: 0.156-10 ng/mL), and CASP-1 (sensitivity: $5.5 \mathrm{pg} / \mathrm{ml}$, range: $39.06-2500 \mathrm{pg} / \mathrm{ml}$ ) and cytokines IL-1 1 (sensitivity: $5.64 \mathrm{pg} / \mathrm{ml}$, range: $14.06-900 \mathrm{pg} / \mathrm{ml}$ ), IL-6 (sensitivity: $1.6 \mathrm{pg} / \mathrm{ml}$, range: $7.8-500 \mathrm{pg} / \mathrm{ml}), \mathrm{TNF}-\alpha$ (sensitivity: $4.32 \mathrm{pg} / \mathrm{ml}$, range: $15.63-1000 \mathrm{pg} / \mathrm{ml}$ ), IFN- $\gamma$ (sensitivity: $2 \mathrm{pg} / \mathrm{ml}$, range: $12.5-1600 \mathrm{pg} / \mathrm{ml}$ ) and IL-10 (sensitivity: $1.4 \mathrm{pg} / \mathrm{ml}$, range: 9.4-3000 $\mathrm{pg} / \mathrm{ml}$ ). These markers were quantified using Quantikine Human Caspase Immunoassay according to the manufacturer's instructions. Briefly, all reagents and working standards were prepared and the excess microplate strips were removed, before adding $50 \mu \mathrm{L}$ of the assay diluent RD1W to each well. Next, $100 \mu \mathrm{L}$ of standard control for our sample was added per well, after which the well was covered with an adhesive strip and incubated for $1.5 \mathrm{~h}$ at room temperature. Each well was subsequently aspirated and washed twice, for a total of three washes. The antiserum of each molecule analyzed here was added into wells and the plate was covered with a new adhesive strip, and subsequently incubated for $30 \mathrm{~min}$ at room temperature. After this, the aspiration/wash step was repeated, and the CASP-1 conjugate $(100 \mu \mathrm{L})$ was added to each well and incubated for $30 \mathrm{~min}$ at room temperature. The aspiration/wash step was repeated before adding $100 \mu \mathrm{L}$ of substrate solution to each well, followed by incubation at room temperature for additional $20 \mathrm{~min}$. The last step was performed by adding $50 \mu \mathrm{L}$ of stop solution to each well. The optical density was determined within 30 min using a microplate reader set to $450 \mathrm{~nm}$.

\section{Statistical analyses}

The results obtained from all in vitro protocols were analyzed using GraphPad Prism 6 statistical package software. All experiments were performed in independent triplicates, with all protocols performed here, and the data were treated according to good in vitro practices (Griesinger et al., 2016). Based on this, before statistical analysis, most of the data were normalized and transformed to a percentage of control. This type of standardization is currently used in many assays in cell biology, pharmacology and toxicology, where data is generated in which a parameter is measured in a reference system (negative control) and then also under conditions of increasing stress or drug exposure, as previously described by Schott et al. (2018). Briefly, the data were presented as \% mean \pm standard deviation (SD) of the negative or positive control group. Treatments were repeated at least 5 times in each 96-well plate. The upper and lower values of 2-SD range found in these repetitions were considered to be outliers and excluded from the analysis, because these outliers generally generate relative SD $>10 \%$ indicating the presence of some experimental imprecision.

For this reason, all data were presented as a percentage of the control group. In the variable analyzed here, 5-8 replicates were used to obtain median \pm standard deviation (SD) in each replication. Replications of the outlier data were excluded from analysis when triggered $\pm \mathrm{SD}>10 \%$. We believe that this is a stricter procedure than the use of forex exclusion of two standard deviations, which is usually done for the exclusion of outliers. The data were statistically compared by One-way or Two-way analysis of variance followed by Tukey's post hoc tests. The $p$ value was set at 0.05 to indicate statistical significance.

\section{RESULTS AND DISCUSSION}

Initially, the aim of this study was to confirm that this OLZ concentration triggers oxi-inflammatory response of macrophages. OLZ exposure induced higher frequencies of $\mathrm{S}$ and $\mathrm{G} 2 / \mathrm{M}$ cell phases (Fig. 1A, 1B) when compared to the negative control group $(p<0.001)$. This effect was also observed in PHA-exposed cells, despite being more intense in OLZ-exposed macrophages. Morphological alterations associated to inflammatory activation (macrophage spreading pattern) were also observed in cells exposed to this antipsychotic drug, as can be seen in Figure 1C.

From these results, it was possible to evaluate the potential anti-inflammatory effects of açaí on macrophages previously exposed to OLZ antipscychotic 

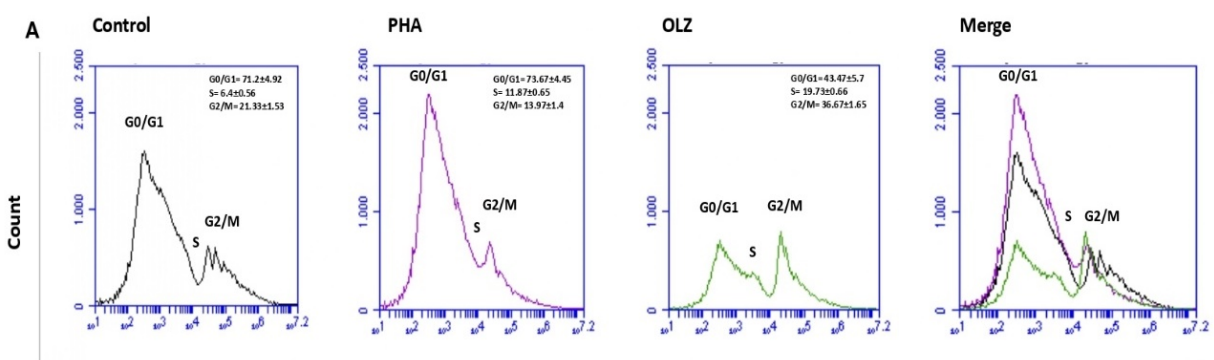

B

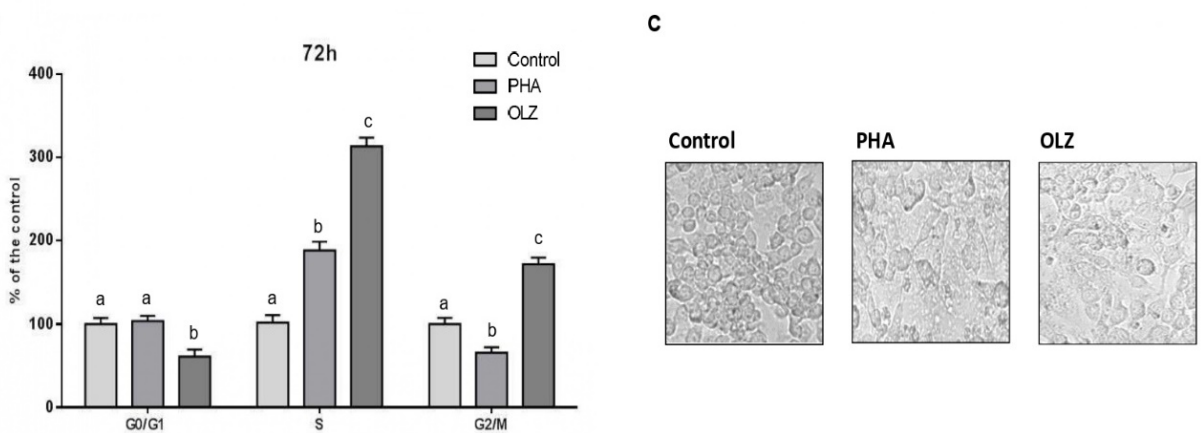

Fig. 1. Effect of OLZ $(0.03 \mu \mathrm{g} / \mathrm{mL})$ on cell cycle modulation and morphological alterations of 72 h cell cultures: A - G0/G1, S and G2/M cell cycle phase frequencies are depicted in figures obtained by flow cytometry analysis. B - modulation of cell cycle phases was compared using a two-way analysis of variance followed by Tukey's post hoc test. Data are presented as percentages of the untreated control group (negative control). $\mathbf{C}$ - pictures show morphological changes caused by PHA and OLZ in macrophage cells after $72 \mathrm{~h}$. Cellular spreading is indicated by red arrows $(\times 40)$, scale bar $=20 \mu \mathrm{m}$. PHA $(125 \mu \mathrm{g} / \mathrm{mL})$ was used as a positive inflammatory control. Control - negative control, PHA - phytohemagglutinin, OLZ - olanzapine. Different letters (i.e., a, b, c, d) indicate significant statistical differences among treatments at $p<0.05$

drugs (Fig. 2). This analysis, non-activated macrophages by PHA, exposed to açai extracts at different concentrations $(0.01 \mu \mathrm{g} / \mathrm{mL})$ didn't presente alterations in cellular proliferation when compared to non-treated control cells. All açai extract concentrations were able to prevent an increase of cellular proliferation triggered by OLZ-exposure $(p<0.001)$.

These results confirmed a previous investigation performed by Machado et al. (2019). These authors described the anti-inflammatory mechanism of açai extract on macrophages activated by phytohemagglutinin (PHA), a natural antigen. In these cultures, açaí extract also caused cell cycle arrest and decreased proliferation.

Results from the two oxidative markers analyzed showed (Fig. 3A) that açai was able to decrease ROS levels just in $>1 \mu \mathrm{g} / \mathrm{mL}$ concentrations $(p=0.01)$.
On the other hand, NO levels returned to similar concentrations observed in the control group when cells were exposed to OLZ and all açai extract concentrations tested here (Fig. 3B).

The antioxidant activity of açai extract has also been well established in previous investigations. In the review performed by Yamaguchi et al. (2015), the authors commented that this effect could be associated with a range of polyphenolic components, including orientin, isoorientin and vanillic acid, as well as anthocyanins cyanidin-3-glucoside and cyanidin-3-rutinoside. These molecules are also found in the açai extract used here and previously described by Machado et al. (2016).

Based on the results obtained from the MTT assay and oxidative markers that are also associated with an inflammatory response, an açaí concentration of $5 \mu \mathrm{g} / \mathrm{mL}$ was chosen to perform additional analysis 


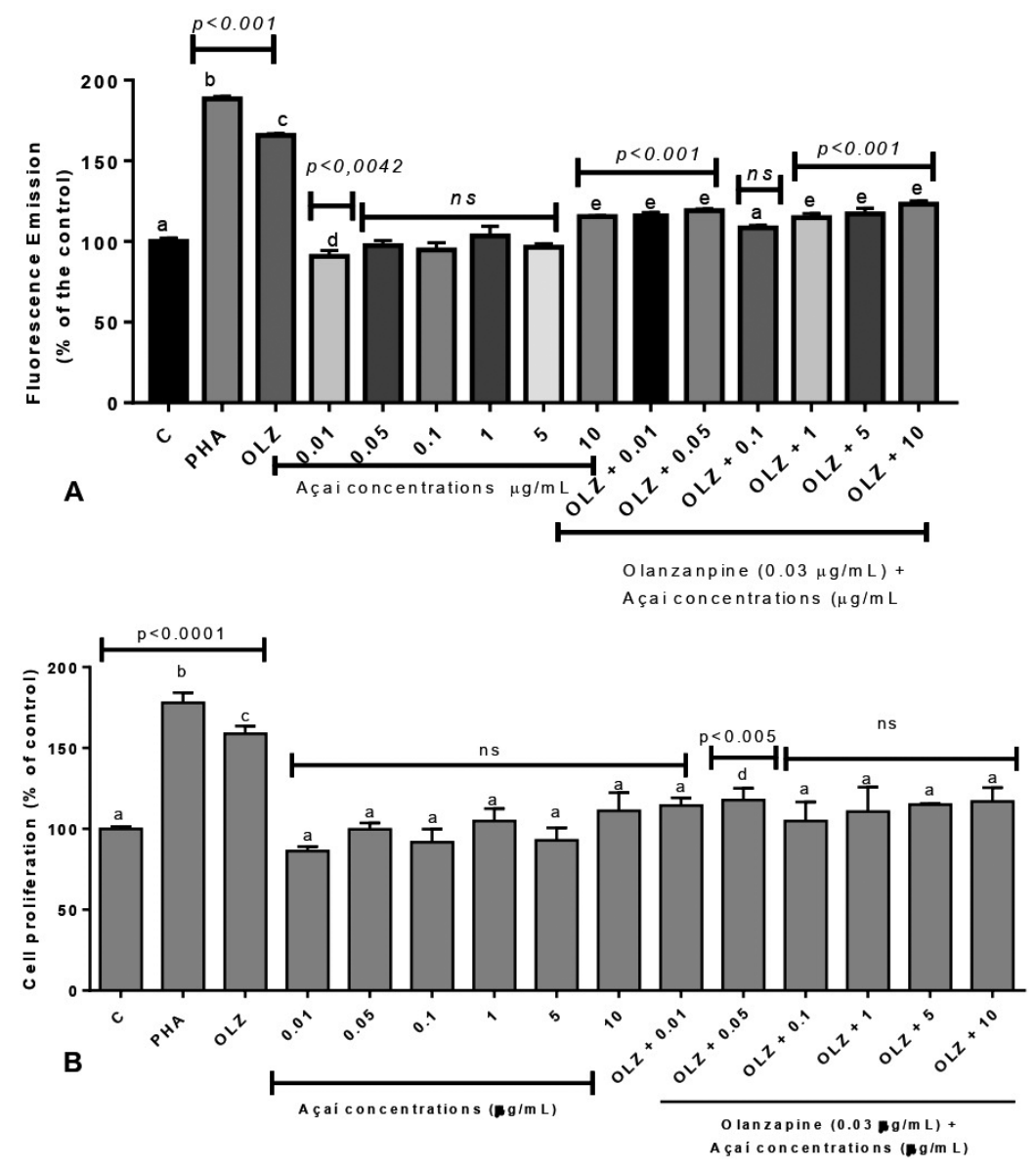

Fig. 2. Cell proliferation of OLZ $(0.03 \mu \mathrm{g} / \mathrm{mL})$, açaí concentration-effect curve $(0.01,0.05,0.1,1,5$, and $10 \mu \mathrm{g} / \mathrm{mL})$ and associations were assessed in macrophages after $72 \mathrm{~h}$ by MTT assay (A) and (B) by Picogreen assay. Data are presented as percentages of the untreated control group (negative control). PHA $(125 \mu \mathrm{g} / \mathrm{mL})$ was used as a positive inflammatory control. Statistical comparison was performed by one-way analysis of variance followed by Tukey's post hoc test. Different letters indicate significant differences. C - negative control, PHA - phytohemagglutinin, OLZ - olanzapine. Different letters (i.e., a, b, c, d) indicate significant statistical differences among treatments at $p<0.05$

of inflammatory modulation markers, including cytokines and caspases (Fig. 4 and 5). In the presence of açai extract at $5 \mu \mathrm{g} / \mathrm{mL}$ IL-1 $\beta$, IL-6 and TNF- $\alpha$ levels decreased significantly when compared to OLZ and PHA-exposed macrophages $(p<0.001)$. However, this effect was partial, since açai extract was not able to revert levels of these pro-inflammatory cytokines to similar values found in the non-activated control macrophages. Açai extract was also able to partially increase the levels of IL-10, an anti-inflammatory cytokine in cells concomitantly OLZ-exposed. Analysis of apoptotic markers showed that açai prevents a significant increase in CASP-1, 3 and 8 triggered in cells just exposed to OLZ.

These results also corroborated the anti-inflammatory action of açai extract described by Machado et al (2019). The authors showed that açai was able to decrease NLRP3 inflammasome levels and reduced 

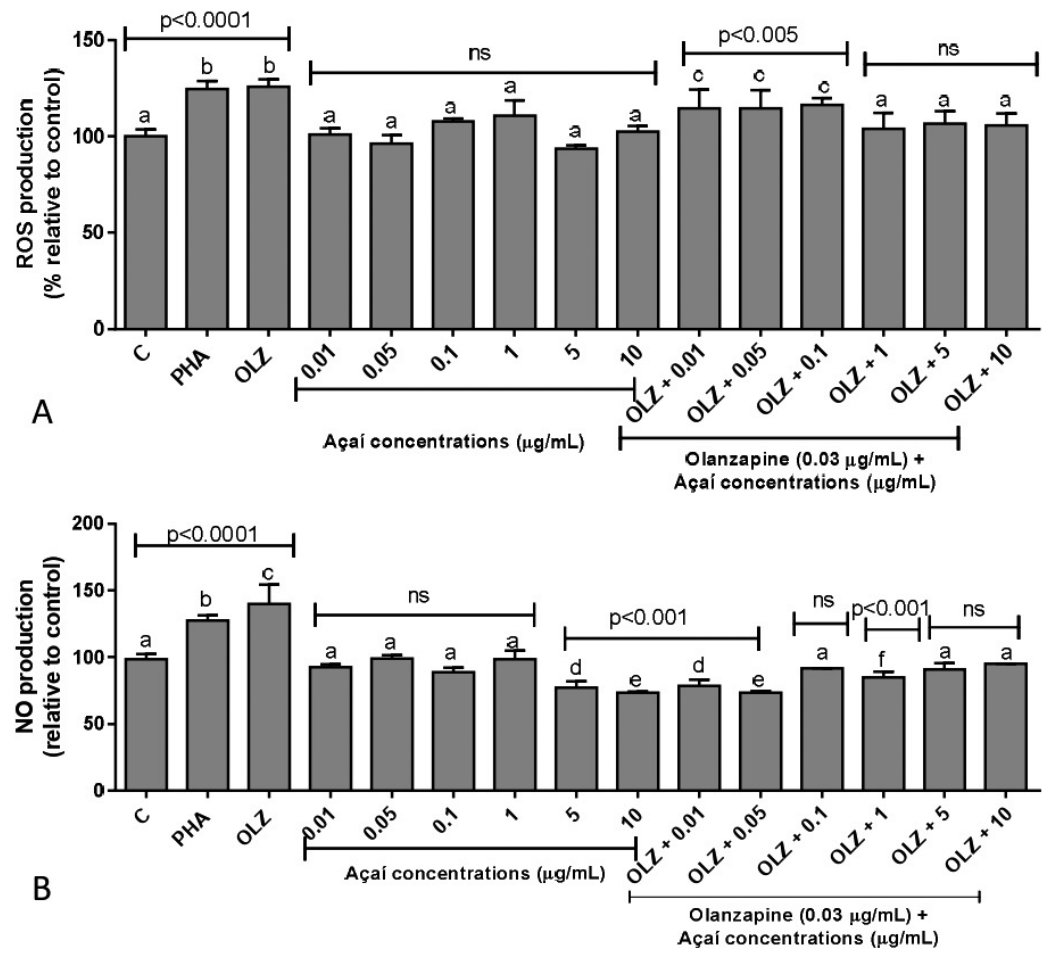

Fig. 3. Oxidative markers. ROS (A) and NO (B) production levels of OLZ $(0.03 \mu \mathrm{g} / \mathrm{mL})$, açaí concentration-effect curve $(0.01,0.05,0.1,1,5$, and $10 \mu \mathrm{g} / \mathrm{mL})$ and associations were assessed in macrophage cells after $72 \mathrm{~h}$. Data were statistically compared by one-way analysis of variance followed by Tukey's post $h o c$ test. Data are presented as percentages of the untreated control group (negative control). PHA $(125 \mu \mathrm{g} / \mathrm{mL})$ was used as a positive inflammatory control. $\mathrm{C}$ - negative control, PHA - phytohemagglutinin, OLZ - olanzapine. Different letters (i.e., a, b, c, d) indicate significant statistical differences among treatments at $p<0.05$

concentrations of the same pro-inflammatory cytokines as those studied here (Fonseka et al., 2016).

The present study evaluated the in vitro effects of açai extract on the proinflammatory response triggered by macrophage-exposure to OLZ. The results suggested that açaí could revert, at least partially, inflammatory states caused by OLZ to pre-exposure levels, suggesting that supplements based in extracts of this fruit richest in anti-inflammatory molecules could be a potential strategy to minimize the side effects triggered by this antipsychotic drug. This assumption is based on the açaí differential effect on cellular proliferation, cytokine modulation, and oxidative stress indicators caused by OLZ.
From these general results, it is important to perform some theoretical and methodological considerations. OLZ is used, among other second-generation antipsychotics (SGA) and first-generation antipsychotics (FGA), as a therapeutic approach for the treatment of schizophrenic-related symptoms. However, some studies have shown that patients under chronic use of antipsychotic drugs, mainly atypical ones, have a tendency to present metabolic alterations, as well as a risk of obesity and cardiovascular disease (Rojo et al., 2015). In this sense, some research has suggested that chronic inflammatory processes may be involved in the mechanisms which trigger obesity, with the contribution of macrophages and inflammatory cytokines 

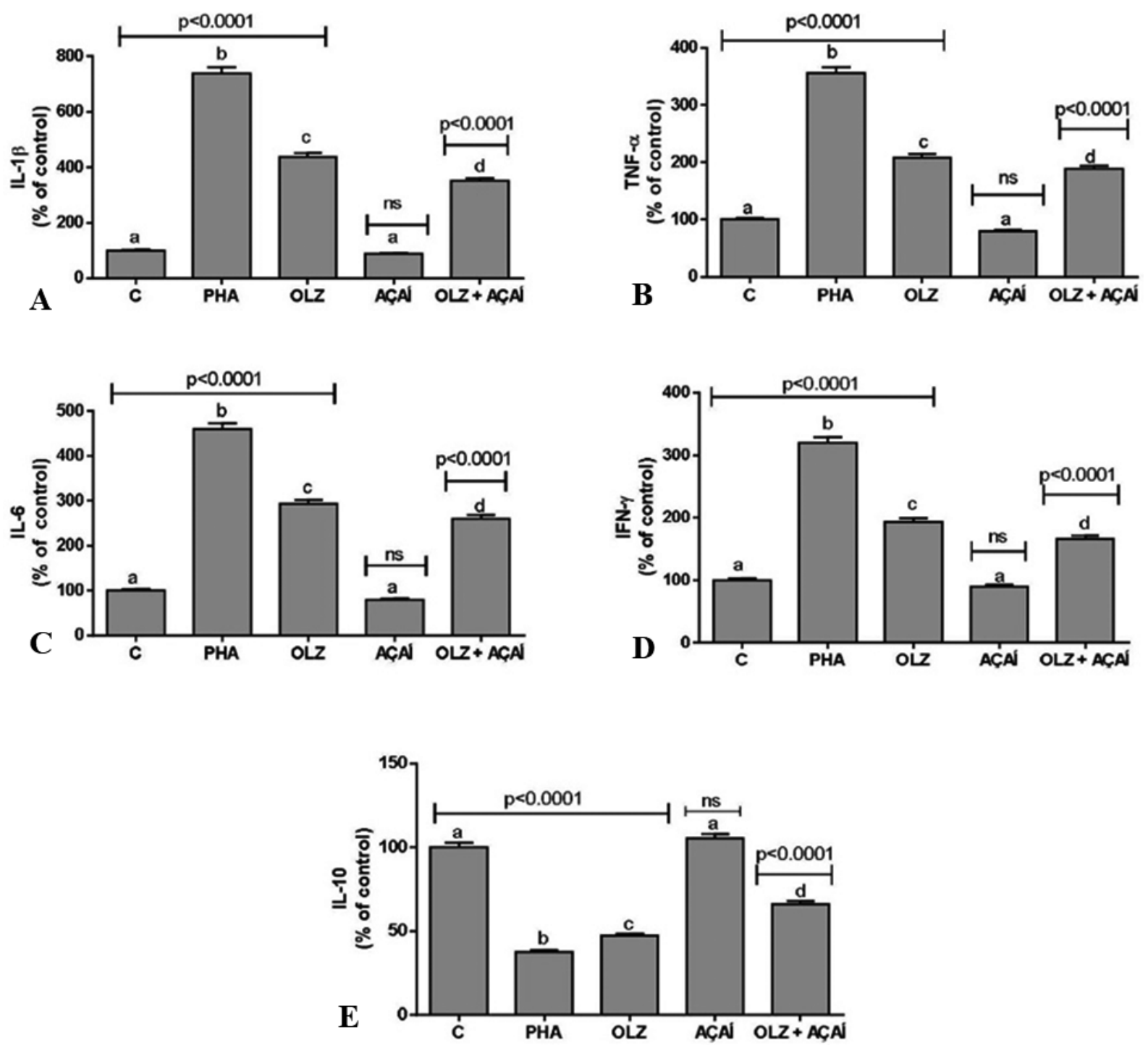

Fig. 4. Effects of OLZ $(0.03 \mu \mathrm{g} / \mathrm{mL})$, açaí $(5 \mu \mathrm{g} / \mathrm{mL})$ and associations on pro-inflammatory (A) IL-1 $\beta,(\mathbf{B}) \mathrm{TNF}-\alpha,(\mathbf{C})$ IL-6, and (D) IFN- $\gamma$ cytokines and anti-inflammatory cytokine (E) IL-10 levels measured by immunoassay in $72 \mathrm{~h}$ cell cultures. The data are presented as percentages of the untreated control group (negative control). PHA $(125 \mu \mathrm{g} / \mathrm{mL}) \mathrm{was}$ used as a positive inflammatory control. $\mathrm{C}$ - negative control, PHA - phytohemagglutinin, OLZ - olanzapine. Different letters (i.e., a, b, c, d) indicate significant statistical differences among treatments at $p<0.05$

(Cildir et al., 2013; Victoriano et al., 2010). It has been speculated whether inflammatory mechanisms may be participating in the increased risks of weight gain and subsequently of obesity resultant from the use of atypical antipsychotics (Gilles et al., 2010; Lord et al., 2017).

In consequence of this process, studies performed using different experimental models have indicated that OLZ triggers a generalized macrophage-infiltration in the adipocyte tissue, increasing the protein and gene expression of proinflammatory cytokines and ROS production (Sárvári et al., 2014; Victoriano et al., 2010). Therefore, the use of RAW macrophage as an experimental model to test the anti-inflammatory effects of açai extract is justified. Previous investigations 


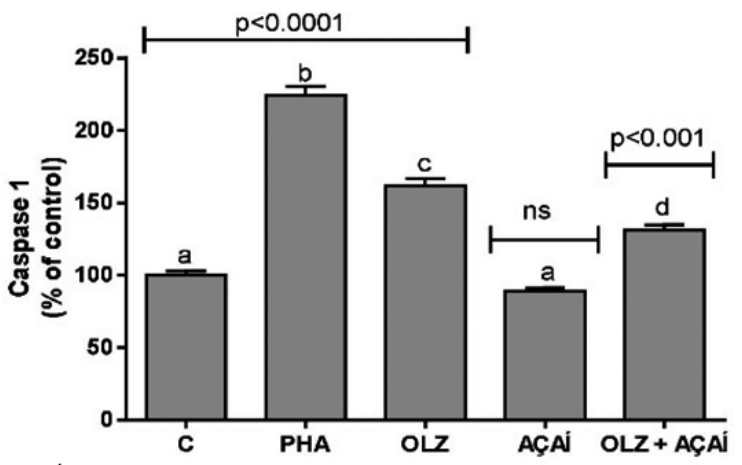

$\mathbf{A}$
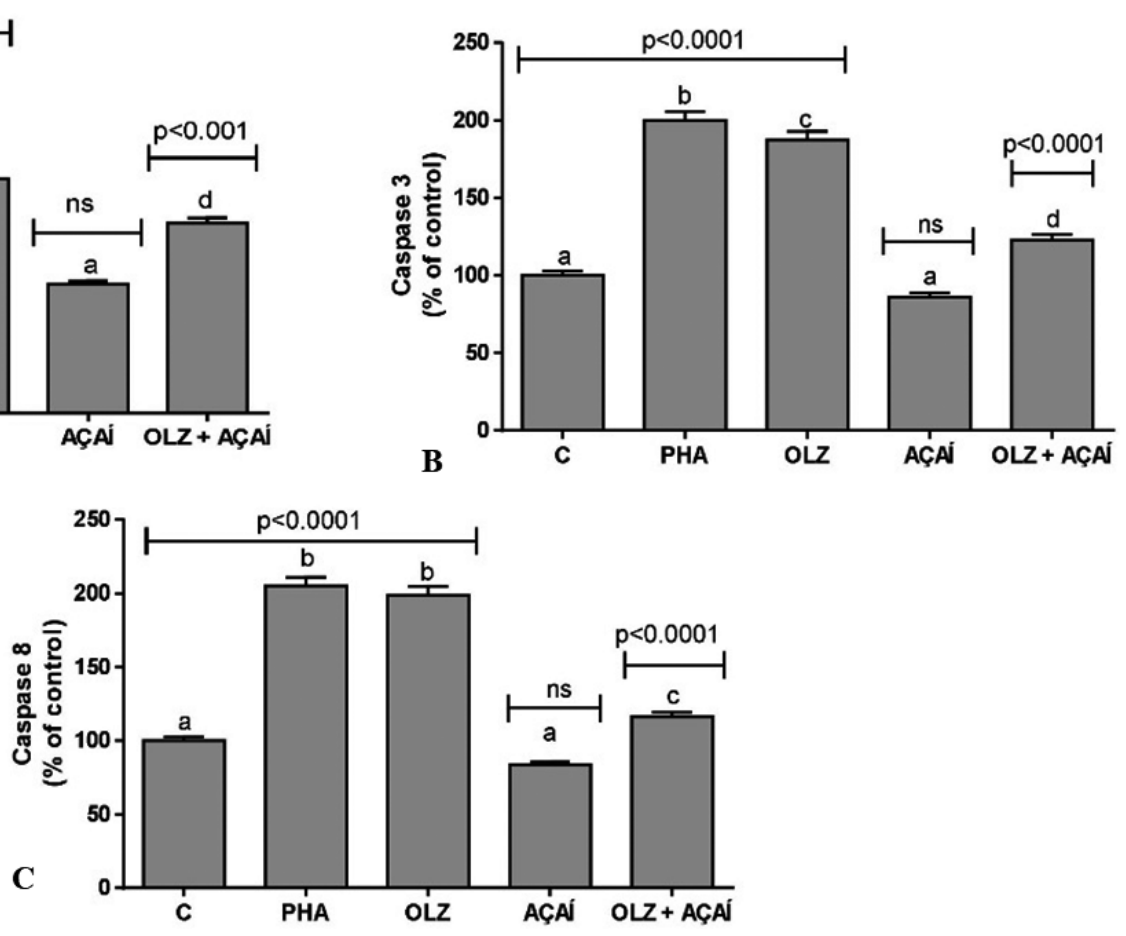

Fig. 5. Effects of OLZ $(0.03 \mu \mathrm{g} / \mathrm{mL})$, açaí $(5 \mu \mathrm{g} / \mathrm{mL})$ and associations on caspase levels $(\mathbf{A}, \mathbf{B}, \mathbf{C})$ measured by immunoassay. The data are presented as percentages. PHA $(125 \mu \mathrm{g} / \mathrm{mL})$ was used as a positive inflammatory control. C - negative control, PHA - phytohemagglutinin, OLZ - olanzapine. Different letters (i.e., a, b, c, d) indicate significant statistical differences among treatments at $p<0.05$

have described that these macrophages can be activated by natural sources, such as PHA and other proinflammatory molecules. The activation induces an increase in some oxidative molecules and proinflammatory cytokines, such as IL-1 $\beta$, IL-6, TNF- $\alpha$ (Da Cruz Jung et al., 2016; Duarte et al., 2018; Fernandes et al., 2019; Fonseka et al., 2016). Therefore, OLZ at $0.03 \mu \mathrm{g} / \mathrm{mL}$, which is a plasmatic therapeutic variation of this drug, was considered a proinflammatory concentration and subsequently used in complementary protocols performed here.

Another important effect of OLZ is with respect to the induction of apoptosis markers in macrophage cells. This effect is significant, as are the immunosuppression and cytotoxic effects of this antipsychotic drug. Considering that the levels of proinflammatory cytokines increased, it is possible to infer that OLZ could trigger an increase in macrophage mortality by apoptosis induction. This presumption is also based on previous investigations that reported OLZ apoptotic effects on the pancreatic $\beta$ cell line in hamsters, which produces insulin. The authors considered that, given clinical observations that some OLZ-treated patients exhibit hyperlipidemia and hyperglycemia without gaining weight, this antipsychotic drug could trigger some damage to the pancreatic $\beta$ cells which may contribute to the undesirable metabolic consequences of OLZ treatment in some cases (Ozasa et al., 2013). However, the main cause of apoptosis induction by OLZ remains to be clarified since previous investigations have not found relevant genotoxic effects triggered by this drug (Togar et al., 2012; Türkez and Toğar et al., 2010).

This general inflammatory framework triggered by OLZ on macrophages was partially reversed when the cells were açai-exposed, as shown in the Figure 6 . The initial results showed that all concentrations of açai extract were able to reduce cellular proliferation to levels similar to those of the control cells. Complementary analysis demonstrated that the açai extract 


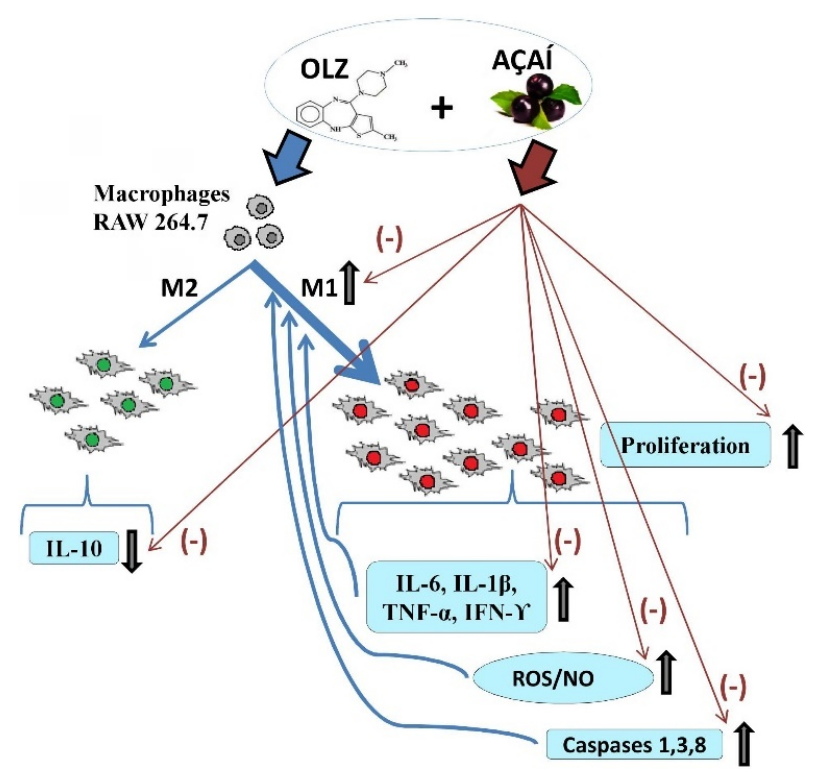

Fig. 6. Synthesis of the main effects of açaí hydro-alcoholic extract $(5 \mu \mathrm{g} / \mathrm{mL})$ on RAW macrophage cells activated by olanzapine (OLZ), an antipsychotic drug at $0.03 \mu \mathrm{g} / \mathrm{Ml}$ concentration. Açai extract was able to partially reduce oxidative, apoptotic and inflammatory markers that are increased in macrophages just exposed to OLZ. M1 - classical via, M2 - alternative via of inflammatory response, IL-1 $\beta$ - interleukin $1 \beta$, IL-6 - interleukin 6 , TNF- $\alpha$ - Tumor Necrosis Factor alpha, IFN- $\gamma$ - interferon gamma, IL-10 - interleukin 10, ROS - Reactive Oxygen Species, NO - Nitric Oxide. Brown arrows with (-) indicate lowering açai effects on oxiinflammatory markers of OLZ-exposed cells, $(+)$ indicate increase in anti-inflammatory marker (IL-10) levels triggered by açai extract on OLZ-exposed macrophages

presented partially attenuated the pro-inflammatory effects of OLZ-induced macrophages.

Moreover, the results could indicate possible subjacent mechanisms involving regulation of classic and alternative inflammatory pathways. In fact, macrophages present a dynamic ability to change their characteristics in response to microenvironmental signals. In this way, these cells can be activated, becoming M1 macrophages that express several proinflammatory cytokines, and can also become M2 macrophages that express anti-inflammatory cytokines. In the M2-phenotype, macrophages inhibit proinflammatory production and trigger regenerative responses in the tissue (Hesketh et al., 2017; Odegaard et al., 2011). Açai seems to act in the two macrophage phenotypes, considering that its supplement decreases proinflammatory cytokines and increases IL-10 levels, which is an anti-inflammatory marker. These results corroborate previous investigations that described, for example, that açai was able to inhibit osteoclast differentiation and activity, which are processes directly associated with inflammatory states (Brito e al., 2016). Studies performed in animal models have also found that açai pulp is able to improve cognition in aged rats and attenuates inflammatory signalling in BV-2 microglial cells (Carey et al., 2017).

The anti-inflammatory effects of açai extract on OLZ-exposed macrophages are possibly a consequence of bioactive molecules present in its chemical matrix (Gouvêa et al., 2012). In particular, the açai extract obtained and used in our experiments has several polyphenols, such as orientin, p-coumaric acid, apigenin, cyanidin-3-0-gluecoside, luteolin, and epicatechin, among others, as previously characterized by Machado et al. (2016). Some of these isolated molecules have already been investigated for possessing key biological properties, for example: (a) orientin presents considerable antioxidant, neuroprotective and anti-inflammatory activities (Lam et al., 2016; Law et al., 2014); (b) p-coumaric acid has important antioxidant properties (Guven et al., 2015); (c) apigenin exerts antioxidant and neuroprotective effects (Heitman and Ingram, 2017; Pápay et al., 2017).

In fact, there are a large number of studies dedicated to identifying bioactive molecules that have isolated anti-inflammatory properties, including the main molecules found in the chemical matrix of açai. For example, Li et al. (2017) also described that apigenin was able to alleviate a myocardial injury induced by lipopolysaccharide exposure by decreasing the levels of oxidative molecules and inflammatory cytokines such as TNF- $\alpha$, IL-1 $\beta$, MIP- $1 \alpha$, and MIP-2. Liu et al. (2017) also showed relevant apigenin protective effects on acute lung injuries and immunotoxicity triggered in paraquat-exposed mice by modulation of oxidative stress and inflammation. Although these studies are relevant, there is also evidence that a food matrix composed of two or more bioactive molecules can have important biological effects, including anticarcinogenic (Niedzwiecki et al., 2016) and anti-inflammatory action (Serrano et al., 2018). 
Therefore, studies involving functional foods such as açai can provide two perspectives in their application: a nutritional approach, where patients can be advised to consume more foods or supplements that have chemical matrices with an effect on the modulation of the immune response, or a pharmacological approach where the molecules identified in fruit can be used for the development of specific anti-inflammatory drugs. In the context of food research, the first approach can be considered relevant because it allows the diet to become an auxiliary factor in the potentiation of a drug or in the mitigation of its adverse effects. This would be the case with açai in relation to the OLZ antipsychotic tested here.

It is possible that these molecules and other minor constituents of the açaí chemical matrix, besides their antioxidant and anti-inflammatory activities reducing ROS, NO and proinflammatory indicator levels, may also modulate other pathways, as observed here. In fact, açaí was able to reduce the expression of caspases 3 and 8, consequently decreasing the proapoptotic signaling pathway triggered by OLZ.

Finally, it is important to point out the methodological constraints of the study presented here. This is an in vitro investigation, and for this reason the results must be considered with prudence, as in vivo systems are more complex and can attenuate or amplify the results described here related to the potential anti-inflammatory effects of açai on OLZ. However, to minimize this main limitation, we conducted our protocol with the RAW 264.7 cell culture considering the large number of studies that have also used this in vitro model to test the potential anti-inflammatory effects of foods, phytotherapies and isolated chemical molecules. Furthermore, it is relevant to comment that early identification of natural food supplements which could attenuate the metabolic side effects triggered by OLZ is difficult to do using in vivo animal models or in humans. This is because, to test a large number of açai concentrations, a large number of animals, like rats and mice, would also be required, making the experiments very expensive, long-term and ethically unacceptable. On the other hand, direct human clinical assays are difficult to perform since in general, patients who use OLZ are polymedicated and/or have several comorbidities. For this reason, the use of an in vitro exploratory approach could be considered a methodological strategy that is relatively easy to carry out, reducing the amount of bias associated with investigations in humans. Therefore, despite these methodological concerns related to in vitro investigations, our results suggest that açai extract could present some therapeutical anti-inflammatory action on the side effects of OLZ triggered in macrophage cells.

\section{CONCLUSIONS}

In summary, the results described here suggest that açai extract could be useful in attenuating the peripheral inflammatory states triggered by use of OLZ in patients with neuropsychiatric diseases, such as schizophrenia, bipolar disorder and dementia. From these results, additional investigations associated with the development of therapeutic açai extract supplements could be useful.

\section{REFERENCES}

Alessandra-Perini, J., Rodrigues-Baptista, K. C., Machado, D. E., Nasciutti, L. E., Perini, J. A. (2018). Anticancer potentialmolecular mechanisms and toxicity of $\mathrm{Eu}$ terpe oleracea extract (açaí): A systematic review. PLoS One, 2, 13(7), e0200101. http://dx.doi.org/10.1371/journal.pone. 0200101

Alqurashi, R. M., Galante, L. A., Rowland, I. R., Spencer, J. P. E., Commane, D. M. (2016). Consumption of a flavonoid-rich açai meal is associated with acute improvements in vascular function and a reduction in total oxidative status in healthy overweight men. Am. J. Clin. Nutr., 104(5),1227-1235. https://doi.org/10.3945/ ajcn.115.128728

Azzolin, V. A., Cadoná, F. C., Machado, A. K., Dal Berto, M., Barbisan, F., Dornelles, E. B., ..., da Cruz, I. B. M. (2016). Superoxide-hydrogen peroxide imbalance interferes with colorectal cancer cells viability, proliferation and oxaliplatin response. Toxicol. Vitro, 32, 8-15. https://doi.org/10.1016/j.tiv.2015.12.00

Barbisan, F., Azzolin, V. F., Teixeira, C. F., Mastella, M. H., Ribeiro, E. E., do Prado-Lima, P. A. S., ..., da Cruz, I. B. M. (2017). Xanthine-catechin mixture enhances lithium-induced anti-inflammatory response in activated macrophages in vitro. Biomed. Res. Int., ID 4151594. https://doi.org/10.1155/2017/4151594

Borges, K. R., Rodrigues, I. V., Pereira, A. L., Silva, X. S., Silva, M. A. C. N., Alves, R.N.S., ..., Bezerra, G. F. B. 
Fernandes, M. S., Machado, A. K., Assmann, C. E., Andrade, E. N., Azzolin, V. F., Duarte, M. M. M. F., Prado-Lima, P. A. S., Riffel, R. T., Maia-Ribeiro, E. A., Cadoná, F. C., Praia, R., Barbisan, F., da Cruz, I. B. M. (2021). Açaí (Euterpe oleracea Mart.) reduces the inflammatory response triggered in vitro by the antipsychotic drug olanzapine in RAW 264.7 macrophage cells. Acta Sci. Pol. Technol. Aliment., 20(2), 149-163. http://dx.doi.org/10.17306/J.AFS.2021.0857

(2019). Euterpe oleracea Mart. inhibits virulence factors of Aspergillus fumigatus. Fut. Microbiol., 14, 717728. https://doi.org/10.2217/fmb-2019-0028

Brito, C., Stavroullakis, A. T., Ferreira, A. C., Li, K., Oliveira, T., Nogueira-Filho, G., Prakki, A. (2016). Extract of açai-berry inhibits osteoclast differentiation and activity. Arch. Oral. Biol., 68, 29-34. https://doi.org/10.1016/j. archoralbio.2016.03.016

Carey, A. N., Miller, M. G., Fisher, D. R., Bielinski, D. F., Gilman, C. K., Poulose, S. M., Shukitt-Hale, B. (2017). Dietary supplementation with the polyphenol-rich açaí pulps (Euterpe oleracea Mart. and Euterpe precatoria Mart.) improves cognition in aged rats and attenuates inflammatory signaling in BV-2 microglial cells. Nutr. Neurosc., 20, 238-245. https://doi.org/10.1080/102841 5X.2015.1115213

Choi, Y. J., Choi, Y. J., Kim, N., Nam, R. H., Lee, S., Lee, H. S., ..., Lee, D. H. (2017). Açaí Berries inhibit colon tumorigenesis in azoxymethane/dextran sulfate sodium-treated mice. Gut Liver., 15, 243-252. https://doi. org/10.5009/gnl16068

Cildir, G., Akıncılar, S. C., Tergaonkar, V. (2013). Chronic adipose tissue inflammation: All immune cells on the stage. Trends Mol. Med., 19, 487-500. https://doi. org/10.1016/j.molmed.2013.05.001

Da Cruz Jung, I. E., Machado, A. K., da Cruz, I. B. M., Barbisan, F., Azzolin, V. F., Duarte, T., ..., Moresco, R. N. (2016). Haloperidol and Risperidone at high concentrations activate an in vitro inflammatory response of RAW 264.7 macrophage cells by induction of apoptosis and modification of cytokine levels. Psychopharmacology, 233, 1715-1723. https://doi.org/10.1007/s00213-0154079-7

Dale, M., Van Duijn, E. (2015). Anxiety in Huntington's disease. J. Neuropsych. Clin. Neurosci., 27, 262-271. https://doi.org/10.1176/appi.neuropsych.14100265

De Almeida Magalhães, T. S. S., Macedo, P. C. O., Converti, A. Neves de Lima, A. A. (2020). The use of Euterpe oleracea Mart. as a new perspective for disease treatment and prevention. Biomolecules, 10, 813. https://doi. org/10.3390/biom 10060813

De Moura, R. S., Resende, Â. C. (2016). Cardiovascular and metabolic effects of açaí, an amazon plant. J. Cardiovasc. Pharmacol., (1), 19-26. https://doi.org/10.1097/ FJC.0000000000000347

De Oliveira, P. R. B., da Costa, C. A., Bem, G. F., Cordeiro, V. S. C., Santos, I. B., de Carvalho, L. C. R. M., ..., Resende, A. C. (2015). Euterpe oleracea Mart.-derived polyphenols protect mice from diet-induced obesity and fatty liver by regulating hepatic lipogenesis and cholesterol excretion. PLoS One, 10, 1-16. https://doi. org/10.1371/journal.pone.0143721

Dias-Souza, M. V., Dos Santos, R. M., Cerávolo, I. P., Cosenza, G., Marçal, P. H. F., Figueiredo, F. J. B. (2018). Euterpe oleracea pulp extract: Chemical analyses, antibiofilm activity against Staphylococcus aureus, cytotoxicity and interference on the activity of antimicrobial drugs. Microbial Pathogenis., 114, 29-35. https://doi. org/10.1016/j.micpath.2017.11.006

Duarte, T., Barbisan, F., do Prado-Lima, P. A. S., Azzolin, V. F., da Cruz Jung, I. E., Duarte, M. M. M. F., ..., da Cruz, I. B. M. (2018). Ziprasidone, a second-generation antipsychotic drug, triggers a macrophage inflammatory response in vitro. Cytokine, 106, 101-107. https://doi. org/10.1016/j.cyto.2017.10.017

Farlow, M. R., Shamliya, T. A. (2017). Benefits and harms of atypical antipsychotics for agitation in adults with dementia. Eur. Neuropsychopharm., 27, 217-231.

Favacho, H. A. S., Oliveira, B. R., Santos, K. C., Medeiros, B. J. L., Sousa, P. J. C., Perazzo, F. F., Carvalho, J. C. T. (2011). Anti-inflammatory and antinociceptive activities of Euterpe oleracea oil. Rev. Farmac., 21,105-114. https://doi.org/10.1590/S0102-695X2011005000007

Feio, C. A., Izar, M. C., Ihara, S. S., Kasmas, S. H., Martins, C. M., Feio, M. N., ..., Fonseca, F. A. (2012). Euterpe oleracea (açai) modifies sterol metabolism and attenuates experimentally-induced atherosclerosis. J. Atheroscler Thromb., 19, 237-245. https://doi.org/10.5551/ jat. 11205

Fernandes, M. S., Barbisan, F., Azzolin, V. F., do PradoLima, P. A. S., Teixeira, C. F., da Cruz Jung, I. E., ..., da Cruz, I. B. M. (2019). Lithium is able to minimize olanzapine oxidative-inflammatory induction on macrophage cells. PLoS One, 29, 14(1), e0209223. https:// doi.org/10.1371/journal.pone.0209223

Fonseka, T. M., Müller, D. J., Kennedy, S. H. (2016). Inflammatory cytokines and antipsychotic-induced weight gain: Review and clinical implications. Mol. Neuropsych., 2, 1-14. https://doi.org/10.1159/000441521

Galling, B., Roldán, A., Nielsen, R. E., Nielsen, J., Gerhard, T., Carbon, M., ..., Correll, C. U. (2016). Type 2 Diabetes Mellitus in youth exposed to antipsychotics: A systematic review and meta-analysis. JAMA Psychiatr., 73, 247-259. https://doi.org/10.1001/jamapsychiatry.2015. 2923

Gilles, M., Hentschel, F., Paslakis, G., Glahn, V., Lederbogen, F., Deuschle, M. (2010). Visceral and subcutaneous fat in patients treated with olanzapine: a case series. Clin. Neuropharmacol., 33(5), 248-249. https://doi.org/ 10.1097/WNF.0b013e3181f0ec33 
Fernandes, M. S., Machado, A. K., Assmann, C. E., Andrade, E. N., Azzolin, V. F., Duarte, M. M. M. F., Prado-Lima, P. A. S., Riffel, R. T., Maia-Ribeiro, E. A., Cadoná, F. C., Praia, R., Barbisan, F., da Cruz, I. B. M. (2021). Açaí (Euterpe oleracea Mart.) reduces the inflammatory response triggered in vitro by the antipsychotic drug olanzapine in RAW 264.7 macrophage cells. Acta Sci. Pol. Technol. Aliment., 20(2), 149-163. http://dx.doi.org/10.17306/J.AFS.2021.0857

Gouvêa, A. C. M. S., de Araujo, M. C. P., Schulz, D. F., Pacheco, S., Godoy, R. L. O., Cabral, L. M. C. (2012). Anthocyanins standards (cyanidin-3-O-glucoside and cyanidin-3-O-rutinoside) isolation from freeze-dried açaí (Euterpe oleraceae Mart.) by HPLC. Ciênc. Tecnol. Aliment., 32, 43-46. https://doi.org/10.1590/S0101-20 612012005000001

Griesinger, C., Desprez, B., Coeck, S., Casey, W., Zuang, V. (2016). Validation of alternative in vitro methods to animal testing: Concepts, challenges, processes and tools. Adv. Exp. Med. Biol., 132, 856-865. https://doi. org/10.1007/978-3-319-33826-2_4

Guven, M., Aras, A. B., Akman, T., Sen, H. M., Ozkan, A., Salis, O., ..., Cosar, M. (2015). Neuroprotective effect of p-coumaric acid in rat model of embolic cerebral ischemia. Iran J. Basic Med. Sci.,18, 356-363.

Halliwell, B., Whiteman, M. (2004). Measuring reactive species and oxidative damage in vivo and in cell culture: how should you do it and what do the results mean? $\mathrm{Br}$. J. Pharmacol., 142, 231-255. https://doi.org/10.1038/ sj.bjp.0705776

Heitman, E., Ingram, D. K. (2017). Cognitive and neuroprotective effects of chlorogenic acid. Nutr Neurosci., 20, 32-39. https://doi.org/10.1179/1476830514Y.00000 00146

Hesketh, M., Sahin, K. B., West, Z. E., Murray, R. Z. (2017). Macrophage phenotypes regulate scar formation and chronic wound healing. Int. J. Mol. Sci., 18(7), 1545. https://doi.org/10.3390/ijms18071545

Komossa, K., Rummel-Kluge, C., Hunger, H., Schmid, F., Schwarz, S., Duggan, L., ..., Leucht, S. (2010). Olanzapine versus other atypical antipsychotics for schizophrenia. Cochr. Database Syst. Rev., 17(3), CD006654. https://doi.org/10.1002/14651858.CD006654.pub2

Krause, M., Zhu, Y., Huhn, M., Schneider-Thoma, J., Bighelli, I., Chaimani, A., Leucht, S. (2018). Efficacy, acceptability, and tolerability of antipsychotics in children and adolescents with schizophrenia: A network meta-analysis. Eur. Neuropsychopharmacol., 28, 659-674. https://doi.org/10.1016/j.euroneuro.2018.03.008

Lam, K. Y., Ling, A. P. K., Koh, R. Y., Wong, Y. P., Say, Y. H. (2016). A review on medicinal properties of orientin. Adv. Pharmacol. Sci., ID 4104595. https://doi. org $/ 10.1155 / 2016 / 4104595$

Larsen, J. R., Vedtofte, L., Jakobsen, M. S. L., Jespersen, H. R., Jakobsen, M. I., ..., Fink-Jensen, A. (2017). Effect of liraglutide treatment on prediabetes and overweight or obesity in clozapine- or olanzapine-treated patients with schizophrenia spectrum disorder: A randomized clinical trial. JAMA Psychiatr., 74, 719-728. https://doi. org/10.1001/jamapsychiatry.2017.1220

Law, B. N., Ling, A. P. K., Koh, K. Y., Chye, S. M., Wong, Y. P. (2014). Neuroprotective effects of orientin on hydrogen peroxide-induced apoptosis in SH-SY5Y cells. Mol. Med. Rep., 9, 947-954. https://doi.org/10.3892/mmr. 2013.1878

Lindström, L., Lindström, E., Nilsson, M., Höistad, M. (2017). Maintenance therapy with second generation antipsychotics for bipolar disorder - A systematic review and meta-analysis. J. Affect. Disord., 213,138-150. https://doi.org/10.1016/j.jad.2017.02.012

Liu, H. J., Fan, Y. L., Liao, H. H., Liu, Y., Chen, S., Ma, Z. G., Zhang, N..., Tang, Q. Z. (2017). Apigenin alleviates STZ-induced diabetic cardiomyopathy. Mol. Cell Biochem., 428(1-2), 9-21. https://doi.org/10.1007/s11010016-2913-9

Lord, C. C., Wyler, S. C., Wan, R., Castorena, C. M., Ahmed, N., Mathew, D., ..., Elmquist, J. K. (2017). The atypical antipsychotic olanzapine causes weight gain by targeting serotonin receptor 2C. J. Clin. Invest., 127, 3402-3406. https://doi.org/10.1172/JCI93362

Machado, A. K., Andreazza, A. C., da Silva, T. M., Boligon, A. A., Nascimento, V., Scola, G., ..., da Cruz, I. B. M. (2016). Neuroprotective effects of acai (Euterpe oleracea Mart.) against rotenone in vitro exposure. Oxidative Med. Cell Longev., ID 8940850. https://doi. org/10.1155/2016/8940850

Machado, A. K., Cadoná, F. C., Assmann, C. E., Andreazza, A. C., Duarte, M. M. M. F., Dos Santos Branco, C., ..., Da Cruz, I. B. M. (2019). Açaí (Euterpe oleracea Mart.) has anti-inflammatory potential through $\mathrm{NLRP}_{3}$-inflammasomemodulation.J.Funct.Foods, 56, 364-371.https:// doi.org/10.1016/j.jff.2019.03.034

Mauri, M. C., Paletta, S., Di Pace, C., Reggiori, A., Cirnigliaro, G., Valli, I., Altamura, A. C. (2018). Clinical pharmacokinetics of atypical antipsychotics: An update. Clin. Pharmacokinet., 57, 1493-1528. https://doi. org/10.1007/s40262-018-0664-3

Mosmann, T. (1983). Rapid colorimetric assay for cellular growth and survival: Application to proliferation and cytotoxicity assays. J. Immunol. Meth., 65, 55-63. https:// doi.org/10.1016/0022-1759(83)90303-4

Niedzwiecki, A., Roomi, M. W., Kalinovsky, T., Rath, M. (2016). Anticancer efficacy of polyphenols and their combinations. Nutrients, 8(9), 552. https://doi. org/10.3390/nu8090552

Odegaard, J. I., Chawla, A. (2011). Alternative macrophage activation and metabolism. Ann. Rev. Pathol., 6, 275-297. https://doi.org/10.1146/annurev-pathol-011110-130138 
Fernandes, M. S., Machado, A. K., Assmann, C. E., Andrade, E. N., Azzolin, V. F., Duarte, M. M. M. F., Prado-Lima, P. A. S., Riffel, R. T., Maia-Ribeiro, E. A., Cadoná, F. C., Praia, R., Barbisan, F., da Cruz, I. B. M. (2021). Açaí (Euterpe oleracea Mart.) reduces the inflammatory response triggered in vitro by the antipsychotic drug olanzapine in RAW 264.7 macrophage cells. Acta Sci. Pol. Technol. Aliment., 20(2), 149-163. http://dx.doi.org/10.17306/J.AFS.2021.0857

Ozasa, R., Okada, T., Nadanaka, S., Nagamine, T., Zyryanova, A., Harding, H., ..., Mori, K. (2013). The antipsychotic olanzapine induces apoptosis in insulin-secreting pancreatic $\beta$ cells by blocking PERK-mediated translational attenuation. Cell. Struct. Funct., 38, 183-195. https://doi.org/10.1247/csf.13012

Pala, D., Barbosa, P. O., Silva, C. T., de Souza, M. O., Freitas, F. R.,Volp, A. C. P., ..., de Freitas, R. N. (2018). Açai (Euterpe oleracea Mart.) dietary intake affects plasma lipids, apolipoproteins, cholesteryl ester transfer to highdensity lipoprotein and redox metabolism: A prospective study in women. Clin. Nutr., 37, 618-623. https://doi. org/10.1016/j.clnu.2017.02.001

Pápay, Z. E., Kállai-Szabó, N., Balogh, E., Ludányi, K., Klebovich, I., Antal, I. (2017). Controlled release oral delivery of apigenin containing pellets with antioxidant activity. Curr. Drug Deliv., 14, 145-154. https://doi. org/10.2174/1567201813666160602193047

Rojo, L. E., Gaspar, P. A., Silva, H., Risco, L., Arena, P., Cubillos-Robles, K., Jara, B. (2015). Metabolic syndrome and obesity among users of second-generation antipsychotics: A global challenge for modern psychopharmacology. Pharmacol. Res., 101, 74-85. https://doi. org/10.1016/j.phrs.2015.07.022

Sadowska-Krępa, E., Kłapcińska, B., Podgórski, T., Szade, B., Tyl, K., Hadzik, A. (2015). Effects of supplementation with acai (Euterpe oleracea Mart.) berry-based juice blend on the blood antioxidant defence capacity and lipid profile in junior hurdlers. A pilot study. Biol. Sport., 32(2), 161-168. https://doi. org/10.5604/20831862.1144419

Sárvári, A. K., Veréb, Z., Uray, I. P., Fésüs, L., Balajthy, Z. (2014). Atypical antipsychotics induce both proinflammatory and adipogenic gene expression in human adipocytes in vitro. Biochem. Biophys. Res. Commun., 450(4), 1383-1389. https://doi.org/10.1016/j.bbrc.2014. 07.005

Serrano, A., Ros, G., Nieto, G. (2018). Bioactive compounds and extracts from traditional herbs and their potential anti-inflammatory health effects. Medicines, 5(3), 76. https://doi.org/10.3390/medicines5030076

Schott, K. L., Assmann, C. E., Teixeira, C. F., Boligon, A. A., Waechter, S. R., Duarte, F. A., ..., da Cruz, I. B. M.
(2018). Brazil nut improves the oxidative metabolism of superoxide-hydrogen peroxide chemically imbalanced human fibroblasts in a nutrigenomic manner. Food Chem. Toxicol., 121, 519-526. https://doi.org/10.1016/j. fct.2018.09.038

Tatsch, E., Bochi, G. V., Pereira, R. S., Kober, H., Agertt, V. A., De Campos, M. M. A., ..., Moresco, R. N. (2011). A simple and inexpensive automated technique for measurement of sérum nitrite/nitrate. Clin. Biochem., 44, 348-350. https://doi.org/10.1016/j.clinbiochem.2010. 12.011

Togar, B., Turkez, H., Tatar, A., Kirkpinar, I., Hacimuftuoglu, A., Geyikoglu, F., ..., Dirican, E. (2012). The genotoxic potentials of some atypical antipsychotic drugs on human lymphocytes. Toxicol. Ind. Health., 28(4), 327333. https://doi.org/10.1177/0748233711410919

Türkez, H., Toğar, B. (2010). The genotoxic and oxidative damage potential of olanzapine in vitro. Toxicol. Ind. Health, 26(9), 583-588. https://doi.org/10.1177/ 0748233710373090

Victoriano, M., Beaurepaire, R., Naour, N., Guerre-Millo, M., Quignard-Boulangé, A., Huneau, J.F., ..., Hermier, D. (2010). Olanzapine-induced accumulation of adipose tissue is associated with an inflammatory state. Brain Res., 1350, 167-175 https://doi.org/10.1016/j.brainres.2010. 05.060

Yamaguchi, K. K. D. L., Pereira, L. F. R., Lamarão, C. V., Lima, E. S., da Veiga-Junior, V. F. (2015). Amazon acai: Chemistry and biological activities: A review. Food Chem., 15, 137-151. https://doi.org/10.1016/j.foodchem.2015. 01.055

Yang, X. B., Webb, D., Blaker, J., Boccaccini, A. R., Maquet, V., Cooper, C., Oreffo, R. O. C. (2006). Evaluation of human bone marrow stromal cell growth on biodegradable polymer/Bioglass ${ }^{\circledR}$ composites. Biochem. Biophis. Res. Comm., 342, 1098-1107. https://doi.org/10.1016/j. bbrc.2006.02.021

Yoodee, J., Permsuwan, U., Nimworapan, M. (2017). Efficacy and safety of olanzapine for the prevention of chemotherapy-induced nausea and vomiting: A systematic review and meta-analysis. Crit. Rev. Oncol. Hemat., 112, 113-125. https://doi.org/10.1016/j.critrevonc. 2017.02.017 
